\title{
WORKABLE COMPETITION IN HEALTH CARE: PROSPECTS FOR THE DUTCH DESIGN
}

\author{
FREDERIK T. SCHUT \\ Department of Health Policy and Management (BMG), Erasmus University Rotterdam, P.O. Box 1738, \\ 3000 DR Rotterdam, The Netherlands
}

\begin{abstract}
Since 1989 a gradual restructuring of the Dutch health care system is taking place to realize a multiple choice social health insurance system with workable competition among insurers and among health care providers. This paper investigates whether the structural change will induce the intended competition. An examination of the characteristics of the markets for health insurance, physician services and hospital services in the Netherlands points out that the scope for competition is limited. If competition is to work, rather extensive government regulation to monitor the conduct of both providers and insurers is needed. Without an effective antitrust policy a high degree of concentration and collusion is likely.
\end{abstract}

Key words - health care reform, competition, national health insurance, the Netherlands

\section{INTRODUCTION}

On both sides of the Atlantic, budgetary constraints and demographic and technological change have fuelled a quest for the Holy Grail of an efficient, equitable, affordable and innovative health care system. Because these goals are neither unambiguously defined nor completely compatible, the treasure is hard to find.

Several Western European countries are looking for ways to restructure their health care systems in order to contain costs and to improve efficiency of health care delivery while maintaining universal coverage. The most radical health care reforms are proposed and are currently being implemented in the Netherlands [1] and the United Kingdom [2]. Both reform proposals intend to strengthen the role of market forces in health care. However, where procompetitive adjustments in the U.K. are confined to health care delivery, they comprise both provision and finance of health care in the Netherlands. The different scope reflects the disparate health care financing systems in both countries. Obviously, competition among third party payers is a less straightforward policy option for the centralized tax funded British National Health Service than for the decentralized Dutch health insurance system.

This paper investigates the feasibility of workable competition in the Dutch health care system given its institutional features and historically determincd

*See Scherer and Ross [4, pp. 53-54] for a résumé of the structural, conduct and performance criteria. Market performance is considered to be workable if productive efficiency approaches the best attainable, if output levels and product quality are responsive to consumer demands, if profits are just sufficient to reward investment, efficiency, and socially desirable innovation, and if promotional expenses are not excessive. market structure. Rather than to assess whether competition in the Dutch health care system may improve efficiency or contain costs the objective is to ascertain whether the intended competition among providers and among health insurers is likely to occur at all.

The conditions in the health care industry are remote from those required for the realization of the perfect competition model. Hence, the Dutch health care reform is not aimed at attaining conventional welfare economics' first-best or even second-best solutions to the allocation of health care resources. Instead, the objective of the reform is to create the conditions for 'workable' competition, resulting in an improvement of the overall performance of the health care industry. Although 'competition' is not defined explicitly in the health care reform proposals, its purport is actual or potential rivalry among providers and among health insurers, who are striving independently for the customer's patronage.

The phrase workable competition was coined by Clark, who provided the following generic definition:

competition is rivalry in selling goods, in which each selling unit normally seeks maximum net revenue, under conditions such that the price or prices each seller can charge are effectively limited by the free option of the buyer to buy from a rival seller or sellers of what we think of as 'the same' product, necessitating an effort by each seller to equal or exceed the attractiveness of the others' offerings to a sufficient number of sellers to accomplish the end in view $[3$, p. 243].

For several decades industrial organization economists have been trying to formulate appropriate criteria for judging the workability of competition. These efforts resulted in an extensive list of criteria of market structure and conduct which are expected to be associated with workable performance.* The resulting structure-conduct-performance paradigm 
provides a framework (rather than a precise yardstick) for assessing the likelihood of workable competition in the Dutch health care industry.

The paper is organized as follows. First, a bird'seye view of the Dutch health care system is provided. Then the main features of the Dutch health care reform are described. In subsequent sections the potential impact of the proposed reform on the performance of the markets for health insurance, physician services and hospital services are discussed.

\section{THE DUTCH HEALTH CARE SYSTEM}

The health care system in the Netherlands is a complex mixture of elaborate government regulation and private enterprise. A distinguishing feature of the Dutch system is the strict separation of the financing and delivcry of health care. Social insurance bodies are legally forbidden to employ providers or to run health care institutions and private health insurers have traditionally been anxious not to interfere with medical practice. Despite the predominance of private ownership, the Dutch health carc system is heavily regulated by government. Particularly since the mid-seventies government tried to gain control of the allocation resources in health care. As a result the present Dutch health care system is dominated by government regulated cartels of providers and insurers.

\section{Health care financing}

The private origins of the health care financing system are exemplified by the fact that $32 \%$ of the population is currently privately insured for noncatastrophic risks, which is by far the highest percentage in Western Europe. Besides, the compulsory social insurance system for the majority of the public is administered by an originally large-but now

*In spite of the absence of government regulation, private health insurers charged community rated premiums until the 1970s. However, there have been other impediments to tailor premiums to risks, such as the threat to provoke government regulation, social goals of not-for-profit private health insurers, cartel arrangements among more than 20 for-profit private health insurers, and the fact that multiple-line insurance companies consider health insurance a lure to sell more profitable lines of insurance. During the 1970s the increasing cost of medical care made risk selection more and more profitable, which triggered a snowballing process of premium differentiation and market segmentation.

$\uparrow$ The opportunities of risk selection in the Dutch private health insurance market are relatively large because $69 \%$ of all insurance contracts are concluded with individual households [5]. By contrast in the U.S. about $90 \%$ is employment-based group health insurance and more than two-thirds of employees are offered only one plan by their employers [6]. Nevertheless, even there increasing competition among health insurers seems to result in avoidance of high-risk non-group individuals [7] and of small business employee groups [8]. Moreover, risk-selection does occur when employees are offered a multiple option choice $[9,10]$. rapidly diminishing - number of autonomous sickness funds. The only national scheme is the social insurance for catastrophic risks, enacted in 1967, which accounts for about $25 \%$ of total health care expenditures in 1990.

Despite their private offspring sickness funds have become purely administrative bodies. Their eligible population is legally determined. Those who are obliged to enrol in sickness funds are primarily non-government employees, retirees, disabled and unemployed persons (and their dependents), with an income below a yearly adjusted specific level. Benefits package and premiums are uniformly dictated. Premiums are paid into a general fund, administered by the Sickness Fund Council, a central regulatory body. Until 1990 Sickness funds were not at financial risk because they are retrospectively fully reimbursed for the medical expenses of their enrolees. Furthermore, sickness funds had very limited power to influence medical practice because of a legal obligation to contract with all providers in their region at nationally determined uniform conditions. Finally, owing to a legally established territorial division of the market nearly all sickness funds had a regional monopoly.

By contrast, more than 60 private insurers, both for-profit (stock) and not-for-profit (mutual) companies, vigorously compete for a share of the remaining part of the health insurance market. Although competition among private health insurers is intense, it is directed to a rather small part of the insured population. For people over the age of 40 , switching to another insurer is very expensive because insurers charge age-related entrance-premiums to mitigate adverse selection problems. Until the mid-eighties, there was little government regulation of the private insurance market. As a result of continuing price competition among private health insurers since the beginning of the seventies, the historically rather undifferentiated premium structure rapidly became increasingly risk-related.* Once initiated, the process of cream-skimming (by insurers) and adverse selection (by consumers) induced an accelerating differentiation of premiums and benefit packages. $\dagger$ The rapid increasing premiums for the elderly and other highrisk groups were jeopardizing the preservation of universal coverage. Therefore, in 1986 the Health Insurance Access Act (WTZ) was adopted to maintain the access to private health insurance. Private insurers were obliged to offer specified risk groups a comprehensive benefits package for a legally determined maximum premium. The eligible population for this 'standard benefits policy' was extended in 1989 to all people over the age of 65 and in 1991 to all private insureds who pay more than the maximum standard premium. Because the imposed maximum premium is far below the actuarial fair level, insurers incur losses on the standard benefits policies. These deficits are pooled and levied on all private insureds. Because in 1991 already $35 \%$ of total claims were caused by standard policy holders, private insurers 
have become regulated administrative bodies for a substantial part of their business. So, independent from the health care reform, there is a clear tendency to socialize private health insurance in order to maintain universal financial access to health care.

\section{Health care delivery}

The health care delivery system is an even more confusing amalgam of government regulation and private initiative. Most physicians operate as a selfemployed entrepreneur. There is a sharp distinction between general practitioners and medical specialists. Sickness funds and most private health insurers require that patients must have a referral from a general practitioner before consulting a specialist. General practitioners are paid on a capitation basis for sickness fund patients and on a fee-for-service basis for privately insured patients. Regardless of the type of insurance most medical specialists are paid feefor-service, whereas private fees are on average about twice as high as the fees for sickness fund patients. Fees and capitation payments are uniformly determined through a legally prescribed negotiation process. Based on the Health Care Tariffs Act (WTG) of 1980 a specially appointed autonomous body, the Central Office on Health Care Tariffs (COTG), sets out guidelines for the composition and calculation of tariffs. After approval by the government these guidelines are used by representative organizations of providers and insurers to negotiate the actual charges which in turn have to be approved by the COTG. The associations of general practitioners and specialists on the one hand and those of sickness funds and private health insurers on the other hand are designated by law as representative negotiators. Although the government left very little room for true negotiations the formal institution of a bilateral monopoly considerably reinforced the power of the providers' and insurers' associations.

In contrast to the strong interference with price of physician services, government did not attempt to control output. So, in spite of the price regulation the system is still open to cost inflation. However, by restricting the supply of physicians the government tried to control output indirectly. Since 1986 entry of general practitioners is controlled by a practice location regulation determining the minimum and maximum permitted practice size. In addition, the government can control the supply of medical specialists because specialist positions in hospitals need government approval in order to get reimbursement by the sickness funds. Furthermore, the government has restricted the entry to medical schools and supports the reduction of the resident training

*The successive government proposals 'Change Assured' (1988) and 'Working on Health Care Innovation' (1990) delineate the objectives and time schedule of the health care reform. capacity which is controlled by the professional associations [11].

Most hospitals in the Netherlands are established and maintained by voluntary organizations. Although only few hospitals are actually owned by either municipalities, provinces or the state, government influence upon the hospital sector is pervasive. Up till now, prices, production and capacity of Dutch hospitals are all subject to government regulation. Hospital capacity is strictly regulated by the Hospital Facilities Act (WZV). Before hospital construction may take place a government licence must be obtained. To establish production volume and prices, hospitals have to negotiate an annual budget with the local sickness funds and representatives of private health insurers. The room for negotiation is limited by the budget guidelines of the COTG. Once the annual budget has been approved by the COTG, hospital prices and production targets are determined.

\section{HEALTH CARE REFORM}

Since 1989 the Dutch health care system has been gradually moving towards a more competitive structure. The restructuring is based on the recommendations by the so-called Dekker Committee in 1987, which are laid down in a report entitled 'Willingness to Change'. With some revisions these proposals were endorsed by two consecutive coalition cabinets, together covering nearly the whole political spectrum.*

For the following four main reasons the health care reform was thought to be necessary [1]. First, the results of detailed government regulation of prices and capacity were generally disappointing. Next, the present fragmented health care financing structure effectuates an inefficient allocation of resources because the choice of treatment is often more directed by the source of payment than by considerations of cost-effectiveness. A third reason for the proposed health care reform is the lack of incentives for efficiency in the present system. Neither sickness funds nor physicians benefit from a more efficient provision of health care. Finally, problems of securing access to health care due to the accelerating premium differentiation and risk-selection in the private health insurance sector contributed to the widespread belief that a reform of the health care financing system was required. At present the performance of the private health insurance market is considered to be socially counterproductive. A lot of energy is spent on tracing the good risks relative to the existing premium structure, resulting in a socially undesirable reallocation of resources without any significant effect on the efficiency of medical care.

The two key elements of the government's proposals are a compulsory comprehensive 'basic 
insurance' for all citizens and regulated competition among health care providers and among health insurers. The legally mandated benefit package of the basic insurance will cover about $96 \%$ of all medical expenses.* Hence, the present fragmented health insurance system will be replaced by a uniform national insurance scheme. At least $85 \%$ of the cost of the basic benefit package will be paid for by incomerelated premiums, which are collected in a Central Fund. Health insurers will receive a premium replacing risk-adjusted payment per insured from the Central Fund. The amount of money an insurer receives depends on the actuarial group (e.g. age, sex, health status) the insured belongs to. The remaining part of the premium for the basic benefit package will be paid directly by the insured to the insurer. This flat rate premium may vary among insurers according to their ability to contain costs and should leave enough room for price competition. + The new payment mechanism will apply to both sickness funds and private health insurers. Eventually, the legal distinction between sickness funds and private health insurers will be abolished and pcoplc will be free to choose whatever insurer they like. Insurers will be required to accept applicants irrespective of risk or health status. To ensure sufficient market stability this openenrolment requirement will not apply to applicants who want to switch to another insurer less than 2 years after their previous choice.

Since 1990 the system of retrospective reimbursement of sickness funds is gradually replaced by the proposed prospective budgeting system. In the end, sickness funds will be totally at risk for the health care costs incurred by their insureds. Furthermore, by a pivotal amendment of the Sickness Fund Act in January 1992 the legally defined boundaries of the sickness fund regions have been removed and the obligation to contract with all providers at the same conditions has been abolished.

*Of course a comprehensive compulsory benefit package implies some welfare loss since it requires low-risk groups to purchase too much health insurance. On the other hand a mandated broad benefit package may generate important welfare gains. First, lowest-cost substitutes will not be ignored because they are not covered as could happen in case of a narrow benefit package. Second, the problem of potential free rider behavior is avoided. Finally, because of the standardized benefits, the information on price and quality of insurer services is relatively easy to compare.

†Notice that in the U.S. the average employer contribution to the health insurance premiums of their employees amounts to approximately $90 \%$ for individual coverage and $75 \%$ for family coverage [12]. Several studies indicate that employees are very sensitive to out-of-pocket premium differentials [13-15].

$\ddagger$ In the Netherlands several research projects are in progress to determine a workable formula [16]. Besides there is a fast growing literature on the same subject in the U.S., stemming from the need to develop a proper formula for paying HMOs to provide care to Medicare beneficiaries [17].
The key function of the Central Fund is to combine equity and efficiency. Equity is introduced by incomerelated premiums that are independent of age and health status. By adjusting the progressiveness of the income-related premiums any desired level of cross-subsidies from high to low income groups can be established. The risk-adjusted payments from the Central Fund to the insurers should neutralize insurers' incentives for preferred risk-selection (i.e. selection of favorable risk groups relative to the premium) and provide them with incentives to improve the efficiency of health care delivery. $\neq$

The mandated basic benefit package will not be described in institutional but in functional terms. What matters is no longer the type of provider but only the type of care that is covered. This is expected to increase the substitutability of health care services. Insurers are supposed to become a powerful prudent buyer on behalf of their insureds, collecting and using information about provider behavior to select efficient and high quality health care providers. The basic idea is to provide consumers and representative consumer organizations with incentives and information to select cost-effective health insurers, which in turn get freedom to negotiate contracts with providers. If there is enough competition in both the market for health insurance and that for health care delivery, consumers should motivate insurers to select cost-effective providers. By the abolition of the legal contracting obligation for sickness funds and the partial deregulation of fees of health care providers in 1992, two important preconditions for selective contracting have recently been fulfilled. The effect of these measures will be noticeable after 2 years' transition period, during which the existing contracts have to be maintained.

The health care reform proposals comprise a considerable deregulation of the hospital industry. First, the Hospital Facilities Act will be confined to the planning of large hospital facilities. Next, negotiations between hospitals and health insurers will no longer be subject to detailed guidelines. The transition to a system of free negotiations will be gradual because it will take time to correct the currently distorted purely administrative hospital prices. Therefore, in the short run the recently refined global budgeting system will be maintained. The government aims at full implementation of the reforms by the beginning of 1995 . However, given the number of complicated problems that have to be solved this time horizon appears to be too optimistic.

\section{PROSPECTS FOR WORKABLE COMPETITION}

Even if the generation of a proper risk-adjusted payment system to compensate insurers will succeed and satisfactory solutions to other technical problems will be found, the question remains whether the restructuring of the health care system will indeed lead to workable competition among the participants. 
Table 1. Dutch private health insurance: market concentration in 1986 and $1992^{a}$

\begin{tabular}{|c|c|c|c|c|c|}
\hline \multicolumn{2}{|c|}{ Largest ten (groups of) health insurers } & \multicolumn{2}{|c|}{$\begin{array}{l}\text { Market share } \\
\text { ( } \% \text { premiums) }\end{array}$} & \multicolumn{2}{|c|}{$\begin{array}{l}\text { Cumulative } \\
\text { market share }\end{array}$} \\
\hline 1986 & 1992 & 1986 & 1992 & 1986 & 1992 \\
\hline 1 Zilveren Kruis & Zilveren Kruis/AVCB & 15.4 & 23.3 & 15.4 & 23.3 \\
\hline 2 OHRA & Nuts-AEGON & 7.9 & 14.7 & 23.3 & 38.0 \\
\hline $3 \mathrm{VGZ}$ & MultiZorg & 6.8 & 14.1 & 30.1 & 52.1 \\
\hline 4 AEGON & OHRA/ZHV & 5.7 & 11.4 & 35.8 & 63.5 \\
\hline 5 Nuts & VGZ/AMEV & 5.4 & 7.5 & 41.2 & 71.0 \\
\hline $6 \mathrm{VGNN}$ & Interpolis/Nw-Rdam ${ }^{b}$ & 5.4 & 6.5 & 46.6 & 77.5 \\
\hline 7 Interpolis & VGNN & 4.1 & 5.4 & 50.7 & 82.9 \\
\hline 8 Delta Lloyd & Univé & 3.1 & 3.6 & 53.8 & 86.5 \\
\hline 9 NNVS & CZ Groep & 3.0 & 3.0 & 56.8 & 89.5 \\
\hline 10 UAP & Zwolsche Algemene & 2.9 & 2.3 & 59.7 & 91.8 \\
\hline
\end{tabular}

An important weakness of the proposals is that a clear link between structure and conduct is missing. The hidden presupposition seems to be that a deregulation of the present legal barriers to competition will compel the desired conduct and performance. However, the same incentives that are supposed to result in competition may also induce collusion with adverse effects on performance. The historically determined structure of the health care industry, which is dominated by cartels that are often instituted or backed by the government, facilitates anticompetitive conduct. A closer look at the features of the markets for health insurance, physician services and hospital services will learn that competition is all but straightforward.

\section{The market for health insurance}

The main reason for reforming the health insurance system is to create the necessary conditions and incentives for a workable species of competition which should be directed at controlling the cost of medical care. On the one hand this implies that health insurers should possess enough market power to affect the price or quality of medical care.* On the other hand, if a health insurer obtains too much buying power, the adverse welfare effects could be considerable [18]. A dominant health insurer can safeguard his position by using his market power to deny medical inputs or to raise their prices to other insurers. Hence, monopsony could become a permanent source of market power. This might not be a problem for unconcentrated health insurance markets, where a dominant position may be very difficult to obtain. However, if for reasons other than market

*In the evident absence of perfect competition among providers, perfect competition among health insurers is not desirable because as price takers they cannot exert any influence on medical practice.

†Both sickness funds and Blue plans are not-for-profit organizations with a historically determined large regional market share; both provide service benefits instead of indemnifying medical expenses and sell no other type of insurance. In addition, the majority of the insurers of both types have agreed not to compete with each other. performance some health insurers have acquired a dominant position, the prospects for workable competition among health insurers might be limited. The Dutch health care reform cannot start at point zero, but has to be built on the historically determined structure of the health insurance industry. This implies that after the reform, sickness funds will be in an advantageous starting position because each sickness fund is located in a separate region in which they typically have more than $60 \%$ market share. Moreover, the health care reform induced a merger wave in the sickness fund sector. Anticipating the loss of their present regional monopolies many sickness funds decided to merge. As a consequence the number of independent sickness funds decreased from 46 in 1987 to only 26 in 1991 . Since most of the mergers involve sickness funds with adjacent working areas the regional market power of sickness funds is further strengthened. Hence the remaining sickness funds may already have a critical buying leverage to drive other insurers out of the local market place. The future market position of the sickness funds may correspond in many aspects to the one presently taken by Blue Cross and Blue Shield plans in the U.S. $\dagger$ In response to the increasing competition from HMOs and PPOs in the eighties, several Blue plans tried to eliminate competitors by using their monopsony power in various ways. Allegations of anticompetitive behavior led to a number of federal antitrust cases against the Blues [19]. Similar problems may arise with respect to the sickness funds.

Contrary to the sickness fund sector, the market for private health insurance was very unconcentrated. The geographic market is much larger because private health insurers can sell their policics all over the country. As shown in Table 1 in 1986 the largest four private health insurers together had a market share of only $35 \%$ [20].

Dutch private health insurers are primarily performing a risk pooling function. Apart from this 'pure' insurance service, health insurers can provide another service, which can be defined as 'cost containment', 'expenditure control' or 'limitation of moral hazard' [21, p. 237]. As all Dutch private 
insurers cover medical expenses rather than providing indemnity insurance, the rationale for cost containment is evident. Despite this fact, very few insurers actively try to manage care for the sake of expenditure control. The main reason seems to be that the originally community rated premium structure still leaves ample room for selecting favorable risks. Consequently preferred risk-selection is considered to be more profitable and less risky than engaging in the unknown area of managing medical practice. Thus conceiving health insurance as a joint product, consisting of variable proportions of risk spreading and cost control, the Dutch private health insurance market is strongly biased towards the former type of service. ${ }^{*}$ Since 'pure' insurance services are easy to imitate and require limited investments, entry barriers are low [21, p. 249] and economies of scale virtually absent [22]. Hence, it is unlikely that any insurer will be able to obtain or retain market power.

The reform of the Dutch health insurance system will have a profound impact on the market structure. If the risk-adjusted payment system to compensate insurers can prevent preferred risk-selection, the main activity of the health insurance business may become expenditure control. For several reasons the cost controlling function requires a considerable minimum scale. First, investments necessary to manage carc, such as recruiting and training staff and purchasing computerized information systems, will increase capital requirements. Significant economies of scale are observed in undertaking cost containment programs by insurers [23]. The increasing economies of scale may put up a barrier to entry for new firms. Second, insurers need enough bargaining power on a local level to negotiate favorable contracts with health care providers. Since bargaining power will be determined by local market share, the relevant geographic market for health insurance will shrink. Instead of the present national market, the future health insurance industry will consist of a number of regional or local submarkets.

In order to survive in such a market private health insurers are actively searching for strategies to increase regional market power. Some of the largest private health insurers that were once established by sickness funds (e.g. Zilveren Kruis and VGZ) have signed agreements to merge with a number of these sickness funds when the legal separation of the two types of insurers is abolished. Since the beginning of the health care reform in 1989 , many insurers with a relatively small share of the health insurance market have decided to sell their policies to one of the larger health insurers. Moreover, most of these larger health

*In the American group health insurance market, where opportunities for preferred risk selection are less extensive than in the individual insurance market, managed care is a rapidly growing activity. In $198872 \%$ of Americans with employer-sponsored coverage were enroled in a managed care plan, as compared with $59 \%$ the year before [12]. insurance companies are involved in mergers or seeking some other form of co-operation. In 1992, seven major multiple-line insurance companies combined forces to establish MultiZorg, an organization for joint negotiating contracts with health care providers, joint purchasing of drugs and medical devices, and for automation support. Owing to this clustering of health insurance activities, market concentration in the private health insurance industry increased dramatically (see Table 1). As a consequence, the present private health insurance market is dominated by four groups of private health insurers.

As remarked earlier, health insurers must have enough countervailing buying power to be able to influence price, quantity and quality of medical care. Hence, particularly among private health insurers the current wave of mergers and joint ventures might be desirable. On the other hand, an ongoing market concentration, especially among sickness funds or among sickness funds and allied private insurers, could result in unbalanced monopsony power with adverse welfare consequences. At present the Dutch government cannot prevent such mergers because the antitrust law does not contain provisions to prohibit mergers or takeovers [24].

\section{The market for physician services}

The Dutch market for physician services has a long-standing tradition of anticompetitive selfregulation. In the twentieth century the medical profession has acquired a substantial control over entry, production, price-setting and financing. Market behavior is regulated by collective bargaining and binding ethical codes of powerful professional associations.

The market power of the medical profession not only stems from self-regulation but, as described earlier, is also strongly enhanced by government regulation. One of the most important sources of market power of physicians is the legal obligation for sickness funds to contract with all physicians in their region on nationally determined uniform conditions. Before this contracting obligation was legalized by the Sickness Funds Decree of 1941, it was the main issue during the pre-war 'battle' between physicians and independent sickness funds. After the Decree physicians no longer needed to compete for a contract with a sickness fund. The main argument of the medical profession for the non-selective contracting obligation for sickness funds was a guaranteed free choice of doctor by the patient. Although patients are in principle free to choose providers (within the boundaries of a sickness fund region), they are at the same time deprived of any right or incentive to select providers on the basis of price and efficiency. In the U.S. these anticompetitive effects of the 'free choice' ethics of the American Medical Association led to the somewhat counterintuitive ruling of the Federal Trade Commission in 1979 and the following 1982 Supreme Court decision 
that the free choice requirement violated the antitrust laws [24].

Having regard to the past, the abolition of the legal contracting obligation for sickness funds and the partial deregulation of fees of health care providers are unprecedented. Another noteworthy step is the repeal of the practice location regulation for general practitioners in 1992, which removes an important legal entry barrier. These measures should pave the way for competition among providers in order to get favorable contracts with health insurers.

However, competition is not the only and perhaps not even the most likely responsc to the proposed reforms. At present, individual or local groups of physicians lack any bargaining skills because of the legalized collective negotiations on tariffs and other contractual terms. The Royal Dutch Medical Association (KNMG) has stipulated that in a future health care system collectively negotiated contracts with insurers should be binding for all providers and insurers, resulting in uniform prices on a national level and other uniform contractual conditions on the regional level. Furthermore, the medical profession is anticipating the reforms by reducing the resident training capacity of medical specialists and general practitioners, thereby raising entry barriers and creating scarcity. As a consequence of the manpower planning by the professional associations, the excess supply of general physicians and medical specialists during the eighties was virtually eliminated at the beginning of the nineties. Ironically, for fear of supplier induced demand government policy still encourages and supports capacity reduction of professional education. These conflicting policy objectives demonstrate that Dutch health care policy finds itself in a transition period from a planning-oriented towards a market-oriented approach. However, by a persistent reliance on familiar planning tools, policymakers run the risk to frustrate the workability of the market oriented approach in advance. Besides, the opportunities to counteract anticompetitive physician

*The Hospital Facilities Act requires a new general hospital to have a minimum size of 175 beds, in order to guarantee the availability of two full-time medical specialists of each of the six so-called 'core specialties'.

†Given the rapid consolidation of U.S. hospitals during the eighties, the proportion of hospital monopolies has probably been increased since 1972 .

$\$$ Besides, the propensity to travel may differ in the two countries, probably being higher in the U.S. On the other hand, in the U.S. not only patients and their visitors have to travel, but also their community-based physicians, which is very unusual in the Netherlands. Robinson and Luft [28] assume the willingness of the attending physician to travel to be the major restriction on size of the hospital market.

§The Herfindahl-Hirschman Index is the sum of the squared market shares of all firms in the same relevant product and geographic market. The index varies from approx 0 in an atomistic market to 10,000 in a pure monopoly. An index of 1800 corresponds to a market with about 6 equally sized firms. behavior through the application of antitrust laws are limited as long as the Netherlands remains the cartels' Land of Cockaigne within Europe [24].

\section{The market for hospital services}

The nature of the hospital market provides hospitals with a substantial market power. The service area of most hospitals is limited to an approximate 15 mile (24 $\mathrm{km}$ ) radius [25]. Moreover, hospitals have a considerable minimum size, which severely restricts the maximum number of hospitals within the same geographic market.* Accordingly, the hospital industry is characterized by a high level of market concentration. In comparison to other countries, however, the Dutch hospital industry is relatively unconcentrated thanks to the high population density.

As shown in Table 2, a natural monopoly is a rare phenomenon in the Dutch hospital market [26, 27]. Nine out of ten hospitals in the urbanized Dutch Randstad area, accounting for about $45 \%$ of the population, have more than ten potential competitors in their vicinity. By contrast, already in 1972 nearly a quarter of U.S. hospitals had no potential competitor within a $24 \mathrm{~km}$ radius. $\dagger$ Apart from the large metropolitan areas with more than 30 competing hospitals, the majority of U.S. hospitals-even in the densely populated mid-Atlantic area-face little competition. However, it should be noticed the actual competitive pressure on hospitals may be higher than suggested by these figures because of the rapidly growing number of outpatient substitutes for some hospital services in the U.S. $\neq$

Although the Dutch hospital market structure seems to be more suitable for a market-oriented approach than the American, the market concentration is still high as compared to most other industries. According to the 1984 Merger Guidelines of the U.S. Department of Justice, markets with a Herfindahl-Hirschman Index (HHI) of more than 1800 are regarded as highly concentrated.§ Hence,

Table 2. Distribution of hospitals by the number of other hospitals within $24 \mathrm{~km}$ (15 miles): Comparison between the United States and the Netherlands ${ }^{a}$

\begin{tabular}{|c|c|c|c|c|}
\hline $\begin{array}{l}\text { Other } \\
\text { hospitals }\end{array}$ & $\begin{array}{l}\text { U.S. } \\
(\%)\end{array}$ & $\begin{array}{c}\text { Mid-Atlantic } \\
(\%)\end{array}$ & $\begin{array}{c}\text { Netherlands } \\
(\%)\end{array}$ & $\begin{array}{c}\text { Randstad }^{c} \\
(\%)\end{array}$ \\
\hline 0 & 23.1 & 6.7 & 2.7 & 2.9 \\
\hline 1 & 17.6 & 9.3 & 6.1 & 0.0 \\
\hline $2-4$ & 21.0 & 18.0 & 25.0 & 1.4 \\
\hline $5-10$ & 12.0 & 16.2 & 21.6 & 5.7 \\
\hline $11-15$ & 4.4 & 2.5 & 14.2 & 25.7 \\
\hline $16-20$ & 2.6 & 3.5 & 21.7 & 45.7 \\
\hline $21-25$ & 3.6 & 1.9 & 8.8 & 18.6 \\
\hline $26-30$ & 2.0 & 4.0 & 0.0 & 0.0 \\
\hline$>30$ & 13.7 & 38.0 & 0.0 & 0.0 \\
\hline \multicolumn{4}{|l|}{ Total number } & 70 \\
\hline \multicolumn{5}{|c|}{$\begin{array}{l}\text { "Data relate to } 1972 \text { for the United States and } 1988 \text { for the } \\
\text { Netherlands; U.S. hospitals in Hawaii and Alaska are not } \\
\text { included because of the unique geographic features. } \\
\text { bStates of New York, New Jersey and Pennsylvania. } \\
\text { 'Provinces of North-Holland, South-Holland and Utrecht (account- } \\
\text { ing for } 45 \% \text { of total Dutch population). } \\
\text { Sources: Ref. [26] for U.S. data; Ref. [27] for computation of the } \\
\text { Dutch figures. }\end{array}$} \\
\hline
\end{tabular}


Table 3. Hospital market concentration in the Netherlands in 1984 and $1988^{a}$

\begin{tabular}{|c|c|c|c|c|c|c|c|}
\hline \multirow{2}{*}{$\begin{array}{l}\text { Health region } \\
\text { (Main city) }\end{array}$} & \multicolumn{2}{|c|}{ Number of hospitals } & \multicolumn{2}{|c|}{$\begin{array}{l}\text { Market share } \\
\text { Top two }\left(C_{2}\right)\end{array}$} & \multicolumn{2}{|c|}{$\begin{array}{c}\text { Herfindahl } \\
\text { Index (HHI) }\end{array}$} & \multirow{2}{*}{$\begin{array}{l}\text { Change in } \\
\text { HHI from } \\
1984-1988 \\
\end{array}$} \\
\hline & 1984 & 1988 & 1984 & 1988 & 1984 & 1988 & \\
\hline 01 Groningen & 10 & 9 & 41.0 & 42.4 & 1390 & 1470 & 80 \\
\hline 02 Leeuwarden & 8 & 6 & 34.0 & 55.3 & 1430 & 2280 & 850 \\
\hline 03 Zwolle & 6 & 6 & 60.9 & 58.6 & 2320 & 2230 & -90 \\
\hline 04 Enschede & 6 & 5 & 51.7 & 52.2 & 2160 & 2250 & 90 \\
\hline 05 Apeldoorn & 5 & 3 & 45.3 & 79.8 & 2030 & 3620 & 1590 \\
\hline 06 Arnhem & 11 & 10 & 26.9 & 37.0 & 1000 & 1220 & 220 \\
\hline 07 Nijmegen & 3 & 3 & 89.1 & 89.6 & 4180 & 4260 & 80 \\
\hline 08 Amersfoort & 5 & 5 & 59.3 & 60.8 & 2530 & 2620 & 90 \\
\hline 09 Utrecht* & 11 & 10 & 32.8 & 37.2 & 1140 & 1230 & 90 \\
\hline 10 Hilversum* & 5 & 3 & 55.9 & 83.6 & 2370 & 3790 & 1420 \\
\hline 11 Alkmaar* & 4 & 3 & 67.7 & 81.3 & 3160 & 3830 & 670 \\
\hline 12 Haarlem* & 8 & 8 & 39.3 & 38.8 & 1440 & 1430 & -10 \\
\hline 13 Amsterdam* & 16 & 13 & 29.1 & 33.7 & 920 & 1070 & 150 \\
\hline 14 Leyden* & 4 & 4 & 73.7 & 72.6 & 3350 & 3250 & -100 \\
\hline 15 The Hague* & 8 & 8 & 41.8 & 41.1 & 1530 & 1520 & -10 \\
\hline 16 Gouda* $^{*}$ & 2 & 2 & 100.0 & 100.0 & 5250 & 5150 & -100 \\
\hline 17 Rotterdam* & 12 & 12 & 31.1 & 31.3 & 1030 & 1050 & 20 \\
\hline 18 Dordrecht* & 6 & 4 & 57.1 & 63.3 & 2170 & 2760 & 590 \\
\hline 19 Middelburg & 7 & 5 & 49.0 & 65.8 & 1820 & 2660 & 840 \\
\hline 20 Breda & 7 & 6 & 45.6 & 48.8 & 1730 & 1990 & 260 \\
\hline 21 Tilburg & 3 & 3 & 84.7 & 85.8 & 3880 & 4120 & 240 \\
\hline 22 Den Bosch & 6 & 6 & 50.1 & 48.9 & 2050 & 2010 & -40 \\
\hline 23 Eindhoven & 6 & 5 & 47.0 & 48.0 & 1910 & 2100 & 190 \\
\hline 24 Roermond & 4 & 4 & 62.8 & 65.2 & 2720 & 2770 & 50 \\
\hline 25 Maastricht & 6 & 5 & 52.4 & 56.1 & 2080 & 2410 & 330 \\
\hline Mean & 6.8 & 5.9 & 53.1 & 59.1 & 2220 & 2520 & 300 \\
\hline SD & 3.2 & 2.9 & 18.5 & 18.9 & 1040 & 1090 & 444 \\
\hline
\end{tabular}

a Market concentration is measured by yearly hospital admissions.

*Health regions in the Randstad area.

Source: Ref.[20].

in those markets even relatively small mergers are judged by their competitive impact. If hospitals are regarded as economic units providing a cluster of services* and the legally defined Dutch 'Health regions' are taken as the relevant geographic hospital

*For the time being, this assumption is appropriate for the present Dutch hospital market, because there are little or no substitutes for their services available outside the hospital. In the U.S. a more differentiated product definition might be necessary, since several hospital services are also provided by a rapidly growing number of ambulatory surgery centers, primary care diagnostic centers, and home health care agencies [29].

tHealth regions were defined for planning purposes in the Dutch Hospital Facilities Act. They were originally determined by minimizing the patient flow across their boundaries. The applied methodology corresponds to the Elzinga-Hogarty approach, by which a market is expanded until the LIFO (little in from outside) and LOFI (little out from inside) statistics exceed some critical cutoff level (usually 75 or $90 \%$ ) [30]. Although the Elzinga-Hogarty approach is not free from criticism [31], this might be largely met by adjusting patient flow statistics for paticits who leave the region only for specialized treatment at tertiary care hospitals [32, pp. 143-145]. When applied to the Dutch Health Regions, the average 1986 LIFO and LOFI percentages, adjusted for the share of academic hospitals, amount to 91.6 and 90.8 respectively (standard deviations being 4.5 and $4.2 \%$ ) [33].

$\ddagger$ Both hospital area definitions are constructed for planning of health facilities. Comparison is justified because each market definition aims to delineate coherent hospital service areas that include the majority of buyers and sellers. markets, $\dagger$ most regional hospital markets in the Netherlands are highly concentrated, as shown in Table 3.

Despite the already high level of regional market concentration, the Dutch hospital industry is undergoing a rapid consolidation process. From 1967 to 1984, 93 hospitals were involved in 43 mergers. After 1984 the average market share of the two largest hospitals in each Health Region increased by more than $10 \%$ in 4 years' time (see Table 3 ). During the last decade, the Dutch government actively supported the consolidation of hospitals. Hospital mergers were considered a useful vehicle to reduce the existing excess capacity.

Hospital mergers could be defended as promoting technical efficiency. However, neither American [34] nor Dutch [35] empirical research has found substantial economies of scale in the production of hospital services. The general conclusion is that economies of scale may exist for small hospitals but that moderate- and large-size hospitals can generally be characterized by constant returns to scale. Thus proceeding consolidations of Dutch hospitals seems to be at odds with the objectives of the health care reform.

The observation that the HHI statistics exceed 1800 in more than $70 \%$ of the Dutch hospital markets, indicates a limited potential for workable competition among hospitals. Nevertheless, the conditions for competition are still considerably better than in California, as illustrated in Table 4 $[20,36] .+$ 
Table 4. Comparison of the Herfindahl-Hirschman indices of Dutch Health Regions in 1988 and Californian Health Facilities Planning Areas in 1980

\begin{tabular}{lccccc}
\hline & \multicolumn{2}{c}{ Dutch Health Regions } & & \multicolumn{2}{c}{ Californian HFPAs } \\
\cline { 2 - 3 } \cline { 5 - 6 } HHI & Number & $\%$ & & Number & $\%$ \\
\hline$<1000$ & 0 & 0.0 & & 2 & 1.5 \\
$1000-1799$ & 7 & 28.0 & & 18 & 13.2 \\
$1800-2499$ & 7 & 28.0 & & 7 & 5.1 \\
$2500-4999$ & 10 & 40.0 & & 41 & 30.1 \\
$5000-9999$ & 1 & 4.0 & & 24 & 17.6 \\
10,000 & 0 & 0.0 & & 44 & 32.4 \\
Total & 25 & 100 & & 136 & 100 \\
\hline
\end{tabular}

Sources: Refs $[20,36]$.

While (natural) monopolies are a common feature of the Californian hospital industry, given that nearly one third of the Health Facilities Planning Areas (HFPAs) have an index of 10,000 , they are nonexistent in the Dutch hospital industry.

This comparison is particularly interesting because the proposed reform of the Dutch hospital market corresponds to a considerable degree to the marketoriented policy for hospitals in California. In June 1982 the Californian legislature passed a law permitting private insurers to contract selectively with hospitals. The legislation paved the way for Preferred Provider Organizations, which channel beneficiaries to selected providers, in exchange for a premium discount or other amenities. In less than 5 years, PPOs acquired a $25 \%$ share of the Californian health insurance market. The first results of empirical research into the effects of the Californian experiment indicate that the selective contracting provision had led to substantial price competition among hospitals, resulting in hospital cost containment relative to the previous period and the rest of the United States $[28,37]$. Furthermore, this effect was found to be positively related to the number of competing hospitals in an area. The cost-reducing effect of the Californian market-oriented program appears to be particularly strong in areas where hospitals have more than 10 neighbors within $24 \mathrm{~km}$. This observation might be an important indication of the effectiveness of the Dutch reforms, since it applies to more than $40 \%$ of Dutch hospitals. As nearly all of these hospitals are located in the Randstad area, the prospects for workable competition in the Dutch hospital market clearly are most favorable in this region. However, the results of the Californian experience should be interpreted with caution. The observed price competition among hospitals might well be only a short term response to the change in

\footnotetext{
*In general, antitrust authorities have not been very successful in challenging mergers, particularly not in areas beset with foreign competition. The apparent success in challenging hospital mergers stems from the structural characteristics of hospital markets. Compared to most manufacturing industries, economically meaningful hospital markets are easier to isolate, because of their relatively easy-to-define products and geographic boundaries.
}

legislation. A case study of a Californian metropolitan city shows that the selective contracting by insurers induced a dramatic change in the structure of a local hospital market [38]. Through affiliation and merger, hospitals tried to remain in control of the market-place. In a few years' time the original 14 independent hospitals had grouped themselves into four hospital systems. The horizontal mergers provided the critical mass for a following wave of vertical integrations to control the supply to the hospital. Eventually, the former highly competitive market was transformed into a differentiated oligopoly in which price competition played a minor role.

In contrast to the Netherlands, U.S. antitrust laws provide rather powerful policy instruments to prevent mergers. In the last decade, competitive pressure on American hospitals has increased dramatically, due to the more and more 'prudent buying' by health insurers, HMOs, PPOs and the federal government (which introduced a prospective payment system for Medicare beneficiaries). The growing competitive pressure induced a 4-fold increase in the number of acquisitions or consolidations, rising to roughly 200 a year in the early 1980 s [32, p. 93]. According to the American Hospital Association 79 hospital mergers occurred between 1982 and 1986. At the same time, antitrust authorities made clear that hospital mergers would be reviewed within the same antitrust framework that applies to any acquisition. In fact, hospital mergers soon became the focus of the Federal Trade Commission and Justice Department merger activities. ${ }^{*}$ In several cases these activities resulted in the divestiture of the challenged hospital merger. Since 1988 , for the first time also consolidations of nonprofit hospitals have been challenged. Although the evidence is not quite clear, the nonprofit status of merging hospitals does not appear to impose a significant restriction on the antitrust review of their actions [32, pp. 112-113].

At present, the Dutch government has no policy instruments to counteract a further consolidation of the Dutch hospital industry, which will be induced by the reforms. Besides, the opportunities for demand substitution outside the hospital are still very small. The lack of sufficient outpatient care substitutes adds to the potential anticompetitive impact of a hospital merger. However, this may turn out to be primarily a short-term problem, because the health care reform will encourage effective demand substitution in several ways. First, the proposed deregulation of the Hospital Facilities Act will create room for the establishment of free-standing outpatient clinics (which at present are legally tied to a hospital). Second, the choice of the most cost-effective type of service is prompted by incorporating nearly all potential substitutes for hospital services in a single comprehensive benefit package.

Another structural feature of hospital markets which limits competition is the existence of considerable entry barriers. Until now, entry to the Dutch 
hospital market is blocked by the Hospital Facilities Act. However, when the proposed deregulation is effectuated, entry will be much easier for most less specialized hospital services. For the more specialized clinical services entry will remain difficult, even apart from the remaining legal barriers. The technological requirements of highly specialized hospitals demand a planning and construction period of between 4 and 9 years $[32$, p. 154]. So the period of entry will be too long to withhold hospitals from raising prices above competitive levels. Moreover, exit from the hospital market is very costly because investments cannot be liquidated without substantial losses. The fact that entry does not mean a credible threat for many hospital services, implies that government should keep a sharp eye on collusion and abuse of dominant positions to keep competition workable.

\section{CONCLUSION}

The Dutch design of a competitive and equitable health care system is gradually leaving the drawing board. The actual implementation of the theoretical concepts is a very complicated process. The creation of the necessary conditions for workable competition in health care not only requires a reshape of the structure of the health care market, but also a dramatic change of conduct of all participants. On the one hand, the structural preconditions for a market-oriented health policy in the Netherlands may be relatively good as compared to other industrialized countries, because of the high population density and the large number of private institutions. On the other hand, the historically determined structure of the health care financing and delivery system, the long-standing tradition of anti-competitive selfregulation and of collective bargaining by government protected cartels of providers and insurers, put significant constraints on the possibility of workable competition.

The analysis of the Dutch health care market shows that if competition is to result in workable performance outcomes, government should set appropriate rules of the game. At least, an effective antitrust policy is required to be able to counteract anticompetitive behavior and monopolization. For health care markets in particular Clark's statement seems to hold that "to keep competition healthy requires the traditional eternal vigilance" [39, p. 462].

Several countries are presently considering market oriented reforms of their health care systems. Because the potential success of a market-oriented health care reform crucially depends on the structural, behavioral and institutional features of the health care system, careful analysis of these conditions should precede a decision to implement such reforms. Eventually, the Dutch 'natural experiment' may provide a crucial test of the feasibility of workable competition in multiple-insurer health care systems.
Acknowledgements-The author wishes to thank Warren Greenberg, Bradford Kirkman-Liff, Wynand van de Ven, René van Vliet and an anonymous referee for their comments on this and earlier drafts.

\section{REFERENCES}

1. Ministry of Welfare, Health and Cultural Affairs. Changing Health Care in the Netherlands. WVC, Rijswijk, 1988.

2. Culyer A. J., Maynard A. K. and Posnett J. W. (Eds) Competition in Health Care: Reforming the NHS. Macmillan, Houndmills, 1990.

3. Clark J. M. Toward a concept of workable competition. Am. Econ. Rev. 30, 241-256, 1940.

4. Scherer F. M. and Ross D. Industrial Market Structure and Economic Performance, 3rd edn. Houghton Miffin, Boston, 1990.

5. Kontaktorgaan Landelijke Organisaties van Ziektekostenverzekeraars. KISG Yearbook 1988. KLOZ, Houten, 1989.

6. Short P. F. and Taylor A. K. Premiums, benefits, and employee choice of health insurance options. $J$. Hlth Econ. 8, 293-311, 1989.

7. Fanara $\mathbf{P}$. and Greenberg W. The impact of competition and regulation on Blue Cross enrollment of non-group individuals. J. Risk Insurance 52, 185-198, 1985.

8. United States General Accounting Office. Health Insurance: Availability and Adequacy for Small Businesses. GAO/T-HRD-90-02, Washington DC, 1990.

9. Schuttinga J. A., Falik M. and Steinwald B. Health plan selection in the federal employces health benefits program. J. Hlth Politics, Policy Law 10, 119-139, 1985.

10. Strumwasser I., Paranjpe N. V., Ronis D. L., McGinnis J., Kee D. W. and Hall $H$. L. The triple option choice: self-selection bias in traditional coverage, HMOs, and PPOs. Inquiry 26, 432-441, 1989.

11. Lapré R. M. and de Roo A. A. Medical specialist manpower planning in the Netherlands. Hlth Policy 15, 163-187, 1990.

12. Gabel J., DiCarlo S., Fink S. and de Lissovoy G. Employer-sponsored health insurance in America. Hlth Affairs 8, 116-128, 1989.

13. Welch $W$. P. The elasticity of demand for health maintenance organizations. J. Hum. Res. 21, 252-266, 1986.

14. Long S. H., Settle R. F. and Wrighton C. W. Employee premiums, availability of alternative plans, and $\mathrm{HMO}$ disenrollment. Med. Care 26, 927-938, 1988.

15. Feldman R., Finch M., Dowd B. and Cassou S. The demand for employment-based health insurance plans. J. Hum. Res. 24, 115-142, 1989.

16. Van Vliet R. C. J. A. and Van de Ven W. P. M. M. Towards a capitation formula for competing health insurers. Soc. Sci. Med. 34, 1035-1048, 1992.

17. Newhouse J. P., Manning W. G., Keeler E. B. and Sloss E. M. Adjusting capitation rates using objective health measures and prior utilization. Hlth Care Financing Rev. 10, 41-54, 1989.

18. Pauly M. V. Market power, monopsony, and health insurance markets. J. Hith Econ. 7, 111-128, 1988.

19. Miller F. H. Vertical restraints and powerful health insurers: exclusionary conduct masquerading as managed care? Law Contemporary Prob. 51, 195-236, 1988.

20. Schut F. T. Mededingingsbeleid in de Gezondheidszorg. VUGA, The Hague, 1989.

21. Pauly M. V. Competition in health insurance markets. Law Contemporary Prob. 51, 237-271, 1988.

22. Blair R. D. and Vogel R. J. A survivor analysis of commercial health insurers. J. Business 51, 521-529, 1978.

23. Feldman R. and Greenberg W. Blue Cross market share, economies of scale, and cost containment efforts. Hlth Services Res. 16, 175-183, 1981. 
24. Schut F. T., Greenberg W. and Van de Ven W. P. M. $M$. Antitrust policy in the Dutch health care system and the relevance of EEC competition policy and U.S. antitrust practice. Hlth Policy 17, 257-284, 1991.

25. Luft H. S., Phibbs C. S., Garnick D. W. and Robinson J. C. Rejoinder to Dranove and Shanley. J. Hlth Econ. 8, 479-483, 1989.

26. Luft H. S. and Maerki S. C. Competitive potential of hospitals and their neighbors. Contemporary Policy Issues 3, 89-102, 1984.

27. Bartels L. P. Instellingen van Intramurale Gezondheids zorg: Basisgegevens 1-1-1988. Nationaal Ziekenhuisinstituut, NZI/88.572, Utrecht, 1988.

28. Robinson J. C. and Luft H. S. Competition, regulation, and hospital costs, 1982 to 1986. J. Am. Med. Assoc. 260, 2676-2681, 1988.

29. Klingensmith J. M. Applying antitrust concepts to the acute care hospital industry: defining the relevant market for hospital services. J. Hlth Politics, Policy Law 13, 153-165, 1988.

30. Elzinga K. G. and Hogarty T. F. The problem of geographic market delineation in antimerger suits. Antitrust Bull. 18, 45-81, 1973.

31. Werden G. J. The limited relevance of patient migration data in market delineation for hospital merger cases. J. Hlth Econ. 8, 363-376, 1989.

32. Baker J. B. The antitrust analysis of hospital mergers and the transformation of the hospital industry. Law Contemporary Prob. 51, 93-164, 1988.

33. Stichting Informatiecentrum voor de Gezondheidszorg. Regio-Atlas 1986: Regionaal gebruik van ziekenhuisbedden in 1986. SIG, Utrecht, 1988.

34. Cowing T. G., Holtmann A. G. and Powers S. Hospital cost analysis: a survey and evaluation of recent studies. In Advances in Health Economics and Health Services Research 4 (Edited by Scheffler R. M. and Rossiter L. F.). JAI Press, Greenwich, 1983.

35. Van Aert J. H. Ziekenhuiskosten in Econometrisch Perspectief. NZI, Utrecht, 1977.

36. Schramm C. J. and Renn S. C. Hospital mergers, market concentration and the Herfindahl-Hirschman Index. Emory Law J. 33, 869-888, 1984.

37. Zwanziger J. and Melnick G. A. The effects of hospital competition and the medicare PPS program on hospital cost behavior in California. J. Hlth Econ. 7, 301-320, 1988.

38. Starkweather D. B. and Carman J. M. Horizontal and vertical concentrations in the evolution of hospital competition. In Advances in Health Economics and Health Services Research 7 (Edited by Scheffler R. M. and Rossiter L. F.). JAI Press, Greenwich, 1987.

39. Clark J. M. Concepts of competition and monopoly; competition: static models and dynamic aspects. Am. Econ. Rev. 45, 450-462, 1955. 